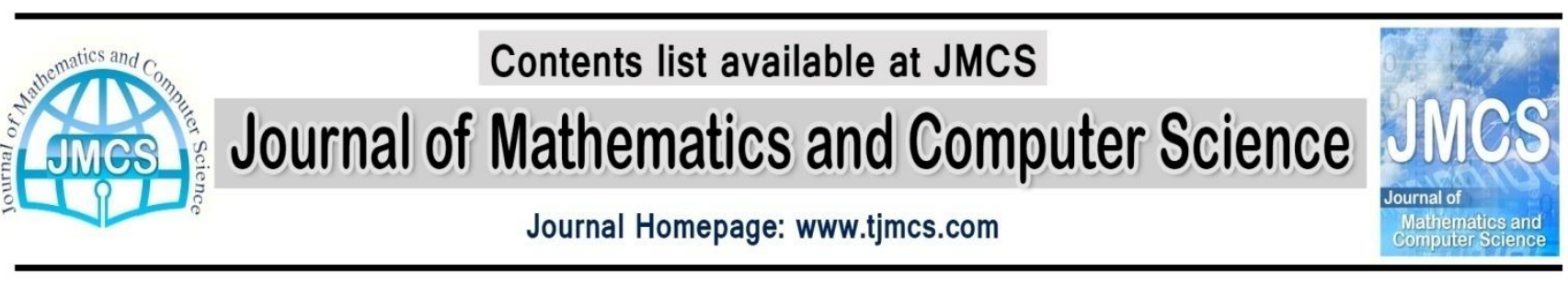

\title{
Some approximated solutions for operator equations by using frames
}

\author{
H. Jamali \\ Department of Mathematics, Vali-e-Asr University of Rafsanjan, Rafsanjan, Kerman, Iran \\ E-mail:jamali@mail.vru.ac.ir
}

Article history:

Received May 2014

Accepted July 2014

Available online August 2014

\begin{abstract}
In this paper we give some approximated solutions for an operator equation $L u=f$ where $L: H \rightarrow H$ is a bounded and self adjoint operator on a separable Hilbert space $H$. We use frames in order to precondition the linear equation so that convergence of iterative methods is improved. Also we find an exact solution associated to a frame and then we seek an approximated solution in a finite dimensional subspace of $H$ that is generated by a finite frame sequence.
\end{abstract}

Keywords: Operator equation, Separable Hilbert space, Frame, Approximated solution.

\section{Introduction}

Our problem is to find $\mathrm{u} \in \mathrm{H}$ such that

$$
\mathrm{Lu}=\mathrm{f} \text {, }
$$

where $\mathrm{L}: \mathrm{H} \rightarrow \mathrm{H}$ is a bounded and self adjoint linear operator on a separable Hilbert space $\mathrm{H}$.

In general it is impossible to find the exact solution of the problem $(1,1)$, because the separable Hilbert space $\mathrm{H}$ is infinite dimensional. A natural approach to constructing an approximate solution is to solve a finite dimensional analog of the problem $(1,1)$. In $[2,6,7,10]$ some approximated solutions for this equation and related problems has been developed by wavelet bases. Usually the operator under consideration is defined on a bounded domain in $\mathbb{R}^{\mathrm{n}}$ or on a closed manifold. Therefore the construction of a wavelet basis with specific properties on this domain or on the manifold is needed. Motivated by some difficulties to construct an appropriate 
basis, we therefore suggest to use a slightly weaker concept namely, frames. In $[8,9,11]$, some iterative methods for solving this system has been developed by frames.

Assume that $H$ is a separable Hilbert space, $\Lambda$ is a countable set of indices and $\Psi=\left(\Psi_{\lambda}\right)_{\lambda \in \Lambda} \subset$ $\mathrm{H}$ is a frame for $\mathrm{H}$. This means that there exist constants $0<\mathrm{A}_{\Psi} \leq \mathrm{B}_{\Psi}<\infty$ such that

$$
\mathrm{A}_{\Psi}\|\mathrm{f}\|_{\mathrm{H}}^{2} \leq \sum_{\lambda \in \Lambda}\left|\left\langle\mathrm{f} \mid \Psi_{\lambda}\right\rangle\right|^{2} \leq \mathrm{B}_{\Psi}\|\mathrm{f}\|_{\mathrm{H}}^{2}, \forall \mathrm{f} \in \mathrm{H},
$$

or equivalently (by the Riesz mapping)

$$
\mathrm{A}_{\Psi}\|\mathrm{f}\|_{\mathrm{H}^{*}}^{2} \leq\|\mathrm{f}(\Psi)\|_{\ell_{2(\Lambda)}}^{2} \leq \mathrm{B}_{\Psi}\|\mathrm{f}\|_{\mathrm{H}^{*}}^{2}, \forall \mathrm{f} \in \mathrm{H}^{*},
$$

where $f(\Psi)=\left(f\left(\psi_{\lambda}\right)\right)_{\lambda}=\left(\left\langle f \mid \psi_{\lambda}\right\rangle\right)_{\lambda}$.

For the frame $\Psi$, let $\mathrm{T}: \ell_{2}(\Lambda) \rightarrow \mathrm{H}$ be the synthesis operator

$$
\mathrm{T}\left(\left(\mathrm{c}_{\lambda}\right)_{\lambda}\right)=\sum_{\lambda \in \Lambda} \mathrm{c}_{\lambda} \psi_{\lambda}
$$

and let $T^{*}: H \rightarrow \ell_{2}(\Lambda)$ be the analysis operator

$$
\mathrm{T}^{*}(\mathrm{f})=\left(\left\langle\mathrm{f} \mid \psi_{\lambda}\right\rangle\right)_{\lambda}
$$

Also let $\mathrm{S}:=\mathrm{TT}^{*}: \mathrm{H} \rightarrow \mathrm{H}$ be the frame operator

$$
S(f)=\sum_{\lambda}\left\langle f \mid \psi_{\lambda}\right\rangle \psi_{\lambda}
$$

Note that $\mathrm{T}$ is surjective, $\mathrm{T}^{*}$ is injective, $\mathrm{T}^{*}$ is the adjoint of $\mathrm{T}$ and because of (1.2), $\mathrm{T}$ is bounded. In fact we have

$$
\|T\|=\left\|T^{*}\right\| \leq \sqrt{B_{\Psi}} .
$$

Since $\operatorname{Ker}(T)=\left(\operatorname{Ran}\left(T^{*}\right)\right)^{\perp}$ then $\ell_{2}(\Lambda)=\operatorname{Ran}\left(T^{*}\right) \oplus \operatorname{Ker}(T)$. It was shown in [5], for the frame $\left(\psi_{\lambda}\right)_{\lambda \in \Lambda}, S$ is a positive invertible operator satisfying $A_{\Psi} I_{H} \leq S \leq B_{\Psi} I_{H}$ and $B_{\Psi}^{-1} I_{H} \leq S^{1} \leq$ $A_{\Psi}^{-1} I_{H}$. Also, the sequence

$$
\widetilde{\Psi}=\left(\tilde{\psi}_{\lambda}\right)_{\lambda \in \Lambda}=\left(S^{-1} \psi_{\lambda}\right)_{\lambda \in \Lambda}
$$

is a frame (called the canonical dual frame) for $H$ with bounds $B_{\Psi}^{-1}, A_{\Psi}^{-1}$. Every $f \in H$ has the expansion

$$
f=\sum_{\lambda}\left\langle f \mid \psi_{\lambda}\right\rangle \tilde{\psi}_{\lambda}=\sum_{\lambda}\left\langle f \mid \tilde{\psi}_{\lambda}\right\rangle .
$$

Also a complete sequence $\left(\psi_{\lambda}\right)_{\lambda \in \Lambda}$ in $H$ is called a Riesz basis if there exist constants $A_{\Psi}, B_{\Psi}>0$ such that

$$
A_{\Psi}\|C\|_{\ell_{2}(\Lambda)}^{2} \leq\left\|\sum_{\lambda} c_{\lambda} \psi_{\lambda}\right\|_{H}^{2} \leq B_{\Psi}\|C\|_{\ell_{2(\Lambda)}}^{2},
$$

hold for all finite sequences $C=\left(c_{\lambda}\right)_{\lambda \in \Lambda}$. Each Riesz basis for a Hilbert space $H$ is a frame for $H$. For more details see [4, 5]. For an index set $\widetilde{\Lambda} \subset \Lambda,\left(\psi_{\lambda}\right)_{\lambda \in \widetilde{\Lambda}}$ is called a frame sequence if it is a frame for its closed span. 


\section{Approximated inverse frames of an operator}

The most straight forward approach to an iterative solution of a linear system is to rewrite the equation (1.1) as a linear fixed-point iteration. One way to do this is the Richardson iteration. The abstract method reads as follows:

write $\mathrm{Lu}=\mathrm{f}$ as

$$
\mathrm{u}=(\mathrm{I}-\mathrm{L}) \mathrm{u}+\mathrm{f}
$$

For given $\mathrm{u}_{0} \in \mathrm{H}$, define for $\mathrm{n} \geq 0$,

$$
u_{n+1}=(I-L) u_{n}+f .
$$

Since $\mathrm{Lu}-\mathrm{f}=0$,

$$
\begin{gathered}
\mathrm{u}_{\mathrm{n}+1}-\mathrm{u}=(\mathrm{I}-\mathrm{L}) \mathrm{u}_{\mathrm{n}}+\mathrm{f}-\mathrm{u}-(\mathrm{f}-\mathrm{Lu})= \\
(\mathrm{I}-\mathrm{L}) \mathrm{u}_{\mathrm{n}}-\mathrm{u}+\mathrm{Lu}=(\mathrm{I}-\mathrm{L})\left(\mathrm{u}_{\mathrm{n}}-\mathrm{u}\right) .
\end{gathered}
$$

Hence

$$
\left\|u_{n+1}-u\right\|_{H} \leq\|I-L\|_{H \rightarrow H}\left\|u_{n}-u\right\|_{H}
$$

so that (2.1) converges if

$$
\|\mathrm{I}-\mathrm{L}\|_{\mathrm{H} \rightarrow \mathrm{H}}<1 .
$$

It is sometimes possible to precondition (1.1) by multiplying both sides by a matrix B,

$$
\mathrm{BLu}=\mathrm{Bf},
$$

so that convergence of iterative methods is improved. This is very effective technique for solving differential equations, integral equations, and related problems [1, 3]. We want to do this by using frames.

Definition 2.1. A frame $\Psi=\left(\psi_{\lambda}\right)_{\lambda \in \Lambda}$ with frame operator $S$, is called an approximated inverse frame of operator $\mathrm{L}$ on $\mathrm{H}$ if $\|\mathrm{I}-\mathrm{SL}\|_{\mathrm{H} \rightarrow \mathrm{H}}<1$.

Richardson iteration, preconditioned with an approximated inverse frame of $\mathrm{L}$, has the following form

$$
\mathrm{u}_{\mathrm{n}+1}=(\mathrm{I}-\mathrm{SL}) \mathrm{u}_{\mathrm{n}}+\mathrm{Sf},
$$

where $S$ is the frame operator of the frame $\Psi$.

Lemma 2.2. Let $\Psi=\left(\psi_{\lambda}\right)_{\lambda \in \Lambda} \subset \mathrm{H}$ be a frame for $\mathrm{H}$ and $\mathrm{L}$ be a bounded operator on $\mathrm{H}$. Then the sequence $\Phi=\left(L \psi_{\lambda}\right)_{\lambda \in \Lambda}$ is a frame for $H$.

Proof. See $[\mathrm{OCH}]$.

Proposition 2.3. If $\Psi=\left(\psi_{\lambda}\right)_{\lambda \in \Lambda}$ is a frame for $\mathrm{H}$ with frame operator $\mathrm{S}$ and $\mathrm{L}$ is a bounded self adjoint operator on $\mathrm{H}$ then $\mathrm{SL}=\mathrm{TT}_{\mathrm{L}}^{*}$, where $\mathrm{T}$ is the synthesis operator of frame $\Psi$ and $\mathrm{T}_{\mathrm{L}}^{*}$ is the analysis operator of frame $\Phi=\left(L \psi_{\lambda}\right)_{\lambda \in \Lambda}$.

Proof. Let $\mathrm{f} \in \mathrm{H}$, then

$$
\operatorname{SLf}=\sum_{\lambda}\left\langle\mathrm{Lf} \mid \Psi_{\lambda}\right\rangle \Psi_{\lambda}=\sum_{\lambda}\left\langle\mathrm{f} \mid \mathrm{L} \psi_{\lambda}\right\rangle \psi_{\lambda}=\mathrm{T}\left(\left\langle\mathrm{f} \mid \mathrm{L} \psi_{\lambda}\right\rangle\right)_{\lambda}=\mathrm{TT}_{\mathrm{L}}^{*} \mathrm{f},
$$


that means $\mathrm{TT}_{\mathrm{L}}^{*}=\mathrm{SL}$.

Using this proposition we can say that a frame $\Psi=\left(\psi_{\lambda}\right)_{\lambda \in \Lambda}$ is an approximated inverse frame of an bounded self adjoint operator $\mathrm{L}$ if $\left\|\mathrm{I}-\mathrm{TT}_{\mathrm{L}}^{*}\right\|_{\mathrm{H} \rightarrow \mathrm{H}}<1$. By taking adjoint this is equivalent to $\left\|\mathrm{I}-\mathrm{T}_{\mathrm{L}} \mathrm{T}^{*}\right\|_{\mathrm{H} \rightarrow \mathrm{H}}<1$.

From linear algebra we know that if $\|\mathrm{I}-\mathrm{SL}\|_{\mathrm{H} \rightarrow \mathrm{H}}<1$ then SL is nonsingular and

$$
(\mathrm{SL})^{-1}=\sum_{\mathrm{n}=0}^{\infty}(\mathrm{I}-\mathrm{SL})^{\mathrm{n}} \text {. }
$$

If $L$ is a bounded self adjoint operator on $\mathrm{H}$ and if $\Psi=\left(\psi_{\lambda}\right)_{\lambda \in \Lambda}$ is an approximated inverse frame of $\mathrm{L}$, then the solution $\mathrm{u}$ of the equation (1.1) is as follow:

$$
\begin{gathered}
\mathrm{u}=(\mathrm{SL})^{-1}(\mathrm{SL}) \mathrm{u}=\sum_{\lambda}\left\langle\mathrm{u} \mid \mathrm{L} \psi_{\lambda}\right\rangle(\mathrm{SL})^{-1} \Psi_{\lambda} \\
=\sum_{\lambda}\left\langle\mathrm{Lu} \mid \Psi_{\lambda}\right\rangle(\mathrm{SL})^{-1} \Psi_{\lambda}=\sum_{\lambda}\left\langle\mathrm{f} \mid \psi_{\lambda}\right\rangle(\mathrm{SL})^{-1} \Psi_{\lambda},
\end{gathered}
$$

also by Proposition 2.3 we have

$$
\mathrm{u}=\sum_{\lambda}\left\langle\mathrm{f} \mid \psi_{\lambda}\right\rangle\left(\mathrm{TT}_{\mathrm{L}}^{*}\right)^{-1} \psi_{\lambda} .
$$

Now we note that each $\mathrm{f} \in \mathrm{H}$ has the representation as

$$
f=\left(T_{L} T^{*}\right)^{-1}\left(T_{L} T^{*}\right) f=\sum_{\lambda}\left\langle f \mid \psi_{\lambda}\right\rangle\left(T_{L} T^{*}\right)^{-1}\left(L \psi_{\lambda}\right),
$$

that means $\left(\mathrm{T}_{\mathrm{L}} \mathrm{T}^{*}\right)^{-1}\left(\mathrm{~L} \psi_{\lambda}\right)$ is a dual frame of the frame $\Psi=\left(\psi_{\lambda}\right)_{\lambda}$. Specially we have the following expansion for the exact solution $u$ of the equation (1.1)

$$
\mathrm{u}=\sum_{\lambda}\left\langle\mathrm{u} \mid \mathrm{L} \psi_{\lambda}\right\rangle\left(\mathrm{T}_{\mathrm{L}} \mathrm{T}^{*}\right)^{-1} \Psi_{\lambda}=\sum_{\lambda}\left\langle\mathrm{Lu} \mid \Psi_{\lambda}\right\rangle\left(\mathrm{T}_{\mathrm{L}} \mathrm{T}^{*}\right)^{-1} \Psi_{\lambda}=\sum_{\lambda}\left\langle\mathrm{f} \mid \Psi_{\lambda}\right\rangle\left(\mathrm{T}_{\mathrm{L}} \mathrm{T}^{*}\right)^{-1} \mathrm{~L} \psi_{\lambda} .
$$

The following theorem tries to approximate $\left(\mathrm{T}_{\mathrm{L}} \mathrm{T}^{*}\right)^{-1} \mathrm{~L} \psi_{\lambda}$.

Theorem 2.4. let $\Psi=\left(\psi_{\lambda}\right)_{\lambda}$ be an approximated inverse frame of a bounded self adjoint operator L. For each $N \in \mathbb{N}$ define

$$
\psi_{\lambda}^{\mathrm{N}}=\sum_{\mathrm{n}=0}\left(\mathrm{I}-\mathrm{TT}_{\mathrm{L}}^{*}\right)^{\mathrm{n}} \psi_{\lambda} .
$$

Then for each $N \in \mathbb{N},\left(\psi_{\lambda}^{N}\right)_{\lambda}$ is a frame for $H$. Also if $T_{N}$ denotes its synthesis operator, then

$$
\left\|\mathrm{I}-\mathrm{T}_{\mathrm{N}} \mathrm{T}_{\mathrm{L}}^{*}\right\|_{\mathrm{H} \rightarrow \mathrm{H}} \leq\left\|\mathrm{I}-\mathrm{TT}_{\mathrm{L}}^{*}\right\|_{\mathrm{H} \rightarrow \mathrm{H}}^{\mathrm{N}+\mathrm{H}} \text {. }
$$

Proof. Let $\mathrm{f} \in \mathrm{H}$,

$$
\begin{aligned}
& \mathrm{T}_{\mathrm{N}} \mathrm{T}_{\mathrm{L}}^{*} \mathrm{f}=\sum_{\lambda}\left\langle\mathrm{f} \mid \mathrm{L} \psi_{\lambda}\right\rangle \psi_{\lambda}^{\mathrm{N}}=\sum_{\lambda}\left\langle\mathrm{f} \mid \mathrm{L} \psi_{\lambda}\right\rangle \sum_{\mathrm{n}=0}\left(\mathrm{I}-\mathrm{TT}_{\mathrm{L}}^{*}\right)^{\mathrm{n}} \Psi_{\lambda} \\
& =\sum_{\mathrm{n}=0}\left(\mathrm{I}-\mathrm{TT}_{\mathrm{L}}^{*}\right)^{\mathrm{n}} \sum_{\lambda}\left\langle\mathrm{f} \mid \mathrm{L} \psi_{\lambda}\right\rangle \psi_{\lambda}=\sum_{\mathrm{n}=0}\left(\mathrm{I}-\mathrm{TT}_{\mathrm{L}}^{*}\right)^{\mathrm{n}} \mathrm{TT}_{\mathrm{L}}^{*} \mathrm{f} \\
& =\sum_{\mathrm{n}=0}\left(\mathrm{I}-\mathrm{TT}_{\mathrm{L}}^{*}\right)^{\mathrm{n}}\left(\mathrm{I}-\left(\mathrm{I}-\mathrm{TT}_{\mathrm{L}}^{*}\right)\right) \mathrm{f}=\mathrm{f}-\left(\mathrm{I}-\mathrm{TT}_{\mathrm{L}}^{*}\right)^{\mathrm{N}+1} \mathrm{f} .
\end{aligned}
$$

Therefore

$$
f-T_{N} T_{L}^{*} f=\left(I-T T_{L}^{*}\right)^{N+1} f \text {, }
$$

that means

$$
\left\|\mathrm{I}-\mathrm{T}_{\mathrm{N}} \mathrm{T}_{\mathrm{L}}^{*}\right\|_{\mathrm{H} \rightarrow \mathrm{H}}=\left\|\left(\mathrm{I}-\mathrm{TT}_{\mathrm{L}}^{*}\right)^{\mathrm{N}+1}\right\|_{\mathrm{H} \rightarrow \mathrm{H}} \leq\left\|\mathrm{I}-\mathrm{TT}_{\mathrm{L}}^{*}\right\|_{\mathrm{H} \rightarrow \mathrm{H}}^{\mathrm{N}+1}<1
$$

Now, we are going to use frames and design an algorithm in order to approximate the solution $u$ of the problem (1.1). This algorithm works based on the frame bounds and frame operator.

Theorem 2.5. Let $\Psi=\left(\Psi_{\lambda}\right)_{\lambda}$ be a frame for $H$ with frame operator $S$ and $L: H \rightarrow H$ be a bounded self 
adjoint operator on $\mathrm{H}$. Suppose that A and B are the bounds of the frame $\Phi=\left(\phi_{\lambda}\right)_{\lambda}=\left(L \psi_{\lambda}\right)_{\lambda}$. Given $\mathrm{u}_{0} \in \mathrm{H}$, define for $\mathrm{n} \geq 1$

$$
\mathrm{u}_{\mathrm{n}}=\mathrm{u}_{\mathrm{n}-1}+\frac{2}{\mathrm{~A}+\mathrm{B}} \mathrm{LS}\left(\mathrm{f}-\mathrm{Lu}_{\mathrm{n}-1}\right)
$$

Then

$$
\left\|\mathrm{u}-\mathrm{u}_{\mathrm{n}}\right\|_{\mathrm{H}} \leq\left(\frac{\mathrm{B}-\mathrm{A}}{\mathrm{B}+\mathrm{A}}\right)\|\mathrm{u}\|_{\mathrm{H}},
$$

so that $u_{n}$ converges to the exact solution $u$ as $n \rightarrow \infty$.

Proof. By definition of $u_{n}$

$$
\begin{gathered}
u-u_{n}=u-u_{n-1}-\frac{2}{A+B} L S L\left(u-u_{n-1}\right) \\
=\left(I-\frac{2}{A+B} L S L\right)\left(u-u_{n-1}\right)=\left(I-\frac{2}{A+B} L S L\right)^{2}\left(u-u_{n-2}\right)=\cdots \\
=\left(I-\frac{2}{A+B} L S L\right)^{n}\left(u-u_{0}\right),
\end{gathered}
$$

thus

$$
\left\|\mathrm{u}-\mathrm{u}_{\mathrm{n}}\right\|_{\mathrm{H}} \leq\left\|\mathrm{I}-\frac{2}{\mathrm{~A}+\mathrm{B}} \mathrm{LSL}\right\|_{\mathrm{H} \rightarrow \mathrm{H}}^{\mathrm{n}}\|\mathrm{u}\|_{\mathrm{H}} .
$$

But for every $\mathrm{v} \in \mathrm{H}$ we have

$$
\begin{gathered}
\left\langle\left(\mathrm{I}-\frac{2}{\mathrm{~A}+\mathrm{B}} \mathrm{LSL}\right) \mathrm{v} \mid \mathrm{v}\right\rangle=\|\mathrm{v}\|_{\mathrm{H}}^{2}-\frac{2}{\mathrm{~A}+\mathrm{B}}\langle\mathrm{LSLv} \mid \mathrm{v}\rangle \\
=\|\mathrm{v}\|_{\mathrm{H}}^{2}-\frac{2}{\mathrm{~A}+\mathrm{B}} \sum_{\lambda}\left|\left\langle\mathrm{v} \mid \phi_{\lambda}\right\rangle\right|^{2} \\
\leq\|\mathrm{v}\|_{\mathrm{H}}^{2}-\frac{2 \mathrm{~A}}{\mathrm{~A}+\mathrm{B}}\|\mathrm{v}\|_{\mathrm{H}}^{2}=\left(\frac{\mathrm{B}-\mathrm{A}}{\mathrm{B}+\mathrm{A}}\right)\|\mathrm{v}\|_{\mathrm{H}}^{2} .
\end{gathered}
$$

The last inequality obtains by the frame property of the frame $\Phi=\left(L \psi_{\lambda}\right)_{\lambda \in \Lambda}$. Similarly we have

$$
-\left(\frac{B-A}{B+A}\right)\|v\|_{H}^{2} \leq\left\langle\left(I-\frac{2}{A+B} L S L\right) v \mid v\right\rangle \text {. }
$$

So we conclude that

$$
\left\|\mathrm{I}-\frac{2}{\mathrm{~A}+\mathrm{B}} \mathrm{LSL}\right\|_{\mathrm{H} \rightarrow \mathrm{H}} \leq \frac{\mathrm{B}-\mathrm{A}}{\mathrm{B}+\mathrm{A}}
$$

Combining this inequality with (2.3) give

$$
\left\|\mathrm{u}-\mathrm{u}_{\mathrm{n}}\right\|_{\mathrm{H}} \leq\left(\frac{\mathrm{B}-\mathrm{A}}{\mathrm{B}+\mathrm{A}}\right)^{\mathrm{n}}\|\mathrm{u}\|_{\mathrm{H}},
$$

and so $\mathrm{u}_{\mathrm{n}}$ converges to $\mathrm{u}$ as $\mathrm{n} \rightarrow \infty$.

\section{Using frames in Galerkin methods}

In this section we will find a sequence of solutions $u_{i}$ of finite dimensional analogs of the problem (1.1), related to the some finite frame sequences, such that converges to the exact solution $\mathrm{u}$ of the problem (1.1). By (1.5), $\mathrm{u}$ has the expansion

$$
\mathrm{u}=\sum_{\lambda \in \Lambda}\left\langle\mathrm{u} \mid \phi_{\lambda}\right\rangle\left(\mathrm{S}^{\prime}\right)^{-1} \phi_{\lambda}
$$

where $\left(\psi_{\lambda}\right)_{\lambda}$ is a frame for $\mathrm{H}$ and $\mathrm{S}^{\prime}$ is the frame operator of the frame $\left(\phi_{\lambda}\right)_{\lambda}=\left(L \psi_{\lambda}\right)_{\lambda}$. Since $\mathrm{L}$ is self adjoint then

$$
\mathrm{u}=\sum_{\lambda \in \Lambda}\left\langle\mathrm{u} \mid \mathrm{L} \psi_{\lambda}\right\rangle\left(\mathrm{S}^{\prime}\right)^{-1} \phi_{\lambda}=\sum_{\lambda \in \Lambda}\left\langle\mathrm{Lu} \mid \psi_{\lambda}\right\rangle\left(\mathrm{S}^{\prime}\right)^{-1}=\sum_{\lambda \in \Lambda}\left\langle\mathrm{f} \mid \psi_{\lambda}\right\rangle\left(\mathrm{S}^{\prime}\right)^{-1} \phi_{\lambda}
$$

Proposition 3.1. Let $\Psi=\left(\psi_{\lambda}\right)_{\lambda} \subset \mathrm{H}$ be a frame for $\mathrm{H}$ and $\widetilde{\Lambda} \subset \Lambda$ be a finite subset of $\Lambda$ such that not all elements of $\Psi_{\widetilde{\Lambda}}=\left(\psi_{\lambda}\right)_{\lambda \in \widetilde{\Lambda}}$ are zero. Then $\Psi_{\widetilde{\Lambda}}$ is a frame sequence.

Proof. See [5]. 
Let $\Lambda_{1} \subset \Lambda_{2} \subset \Lambda_{3} \subset \cdots \nearrow \Lambda$ be finite subsets of $\Lambda$ where not all elements of $\Lambda_{1}$ are zero. By Proposition 3.1 each $\Psi_{\Lambda_{\mathrm{i}}}$ and consequently $\Phi_{\Lambda_{\mathrm{i}}}$ is a frame sequence. We assume that $\Phi_{\Lambda_{\mathrm{i}}}$ are frame sequences with common bounds $\mathrm{A}$ and $\mathrm{B}$. If $\mathrm{L}$ is invertible, it follows that $\Phi_{\Lambda_{\mathrm{i}}}$ are frame sequences with common bounds $\frac{\mathrm{A}}{\left\|\mathrm{L}^{-1}\right\|^{2}}$ and $\mathrm{B}\|\mathrm{L}\|^{2}$. Let $\mathrm{V}_{\mathrm{i}}=\operatorname{span} \Phi_{\Lambda_{\mathrm{i}}}=\operatorname{span}\left(\mathrm{L} \psi_{\lambda}\right)_{\lambda \in \Lambda_{\mathrm{i}}}$ and $S_{i}^{\prime}: V_{i} \rightarrow V_{i}$ be its frame operator, then for every $f \in V_{i}$ we have

$$
S_{i}^{\prime} \mathrm{f}=\sum_{\lambda \in \Lambda_{\mathrm{i}}}\left\langle\mathrm{f} \mid \mathrm{L} \psi_{\lambda}\right\rangle \mathrm{L} \psi_{\lambda}=\mathrm{L}\left(\sum_{\lambda \in \Lambda_{\mathrm{i}}}\left\langle\mathrm{f} \mid \mathrm{L} \psi_{\lambda}\right\rangle \psi_{\lambda}\right)=\mathrm{L}\left(\sum_{\lambda \in \Lambda_{\mathrm{i}}}\left\langle\mathrm{Lf} \mid \psi_{\lambda}\right\rangle \psi_{\lambda}\right)=\mathrm{LS} S_{\mathrm{i}} \mathrm{Lf},
$$

therefore $S_{i}^{\prime}=L_{i} S_{i} L_{i}$, where $L_{i}$ is the restriction of $L$ on $V_{i}$, and $S_{i}$ is the frame operator of the frame sequence $\Psi_{\Lambda_{\mathrm{i}}}$. Specially we obtain $\left(\mathrm{S}_{\mathrm{i}}^{\prime}\right)^{-1}=\mathrm{L}_{\mathrm{i}}^{-1} \mathrm{~S}_{\mathrm{i}}^{-1} \mathrm{~L}_{\mathrm{i}}^{-1}$ and so

$$
\sup _{\mathrm{i} \in \mathbb{N}}\left\|\left(\mathrm{S}_{\mathrm{i}}^{\prime}\right)^{-1}\right\| \leq\left\|\mathrm{L}^{-1}\right\|^{2} / \mathrm{A}, \forall \mathrm{i} \in \mathbb{N} \text {. }
$$

Now we are ready to present the main result that is the following theorem.

Theorem 3.2. Let $\Psi_{\Lambda}, \Phi_{\Lambda}$ and $\Lambda_{\mathrm{i}}$ be as above. Assume that

$$
\mathrm{u}_{\mathrm{i}}=\sum_{\lambda \in \Lambda_{\mathrm{i}}}\left\langle\mathrm{f} \mid \psi_{\lambda}\right\rangle\left(\mathrm{S}_{\mathrm{i}}^{\prime}\right)^{-1} \phi_{\lambda}
$$

then $\mathrm{u}_{\mathrm{i}} \rightarrow \mathrm{u}$ as $\mathrm{i} \rightarrow \infty$.

Proof. Let $\left(c_{\lambda}\right)_{\lambda \in \Lambda} \in \ell_{2}(\Lambda)$ and $\sum_{\lambda \in \Lambda} c_{\lambda} \phi_{\lambda}=0$. Using (3.2) we have

hence

$$
\left\|\left(\mathrm{S}_{\mathrm{i}}^{\prime}\right)^{-1} \sum_{\lambda \in \Lambda_{\mathrm{i}}} \mathrm{c}_{\lambda} \phi_{\lambda}\right\|_{V_{\mathrm{i}}} \leq\left\|\left(\mathrm{S}_{\mathrm{i}}^{\prime}\right)^{-1}\right\|\left\|\sum_{\lambda \in \Lambda_{\mathrm{i}}} \mathrm{c}_{\lambda} \phi_{\lambda}\right\|_{\mathrm{V}_{\mathrm{i}}} \leq\left(\left\|\mathrm{L}^{-1}\right\|^{2} / \mathrm{A}_{1}\right)\left\|\sum_{\lambda \in \Lambda_{\mathrm{i}}} \mathrm{c}_{\lambda \phi_{\lambda}}\right\|_{\mathrm{V}_{\mathrm{i}}},
$$

$$
\left(\mathrm{S}_{\mathrm{i}}^{\prime}\right)^{-1} \sum_{\lambda \in \Lambda_{\mathrm{i}}} \mathrm{c}_{\lambda} \phi_{\lambda} \rightarrow 0 \text {, as } \mathrm{i} \rightarrow \infty \text {. }
$$

Since $\left(\left\langle\mathrm{f} \mid \psi_{\lambda}\right\rangle\right)_{\lambda \in \Lambda} \in \ell_{2}(\Lambda)$ and $\ell_{2}(\Lambda)=\operatorname{Ran}\left(\mathrm{T}^{*}\right) \oplus \operatorname{Ker}(\mathrm{T})$ then

$$
\left(\left\langle\mathrm{f} \mid \psi_{\lambda}\right\rangle\right)_{\lambda \in \Lambda}=\left(\left\langle\mathrm{f}^{\prime} \mid \phi_{\lambda}\right\rangle\right)_{\lambda \in \Lambda}+\left(\mathrm{c}_{\lambda}\right)_{\lambda \in \Lambda}
$$

for some $\mathrm{f}^{\prime} \in \mathrm{H}$ and $\left(\mathrm{c}_{\lambda}\right)_{\lambda \in \Lambda} \in \operatorname{Ker}(\mathrm{T})$. Thus

$$
\sum_{\lambda \in \Lambda_{\mathrm{i}}}\left\langle\mathrm{f} \mid \psi_{\lambda}\right\rangle\left(\mathrm{S}_{\mathrm{i}}^{\prime}\right)^{-1} \phi_{\lambda}=\sum_{\lambda \in \Lambda_{\mathrm{i}}}\left\langle\mathrm{f}^{\prime} \mid \phi_{\lambda}\right\rangle\left(\mathrm{S}_{\mathrm{i}}^{\prime}\right)^{-1} \phi_{\lambda}+\sum_{\lambda \in \Lambda_{\mathrm{i}}} \mathrm{c}_{\lambda}\left(\mathrm{S}_{\mathrm{i}}^{\prime}\right)^{-1} \phi_{\lambda},
$$

therefore

$$
\sum_{\lambda \in \Lambda_{\mathrm{i}}}\left\langle\mathrm{f} \mid \psi_{\lambda}\right\rangle\left(\mathrm{S}_{\mathrm{i}}^{\prime}\right)^{-1} \phi_{\lambda}=\sum_{\lambda \in \Lambda_{\mathrm{i}}}\left\langle\mathrm{f}^{\prime} \mid \phi_{\lambda}\right\rangle\left(\mathrm{S}_{\mathrm{i}}^{\prime}\right)^{-1} \phi_{\lambda}+\left(\mathrm{S}_{\mathrm{i}}^{\prime}\right)^{-1} \sum_{\lambda \in \Lambda_{\mathrm{i}}} \mathrm{c}_{\lambda} \phi_{\lambda} .
$$

Also because of $\left(c_{\lambda}\right)_{\lambda \in \Lambda} \in \operatorname{Ker}(\mathrm{T})$, it follows

$$
\mathrm{u}=\sum_{\lambda \in \Lambda}\left\langle\mathrm{f} \mid \psi_{\lambda}\right\rangle\left(\mathrm{S}^{\prime}\right)^{-1} \phi_{\lambda}=\sum_{\lambda \in \Lambda}\left\langle\mathrm{f}^{\prime} \mid \phi_{\lambda}\right\rangle\left(\mathrm{S}^{\prime}\right)^{-1} \phi_{\lambda}+\left(\mathrm{S}^{\prime}\right)^{-1} \sum_{\lambda \in \Lambda} \mathrm{c}_{\lambda} \phi_{\lambda}=\mathrm{f}^{\prime}
$$

combining this with (3.3) and (3.4) induce the result as $\mathrm{i} \rightarrow \infty$.

Now consider the operator equation (1.1), where $\mathrm{L}$ is a bounded, self adjoint and H-elliptic operator from $\mathrm{H}_{\text {to }} \mathrm{H}^{*}$, that is $(\mathrm{Lv})(\mathrm{v}) \geq \mathrm{C}\|\mathrm{v}\|^{2}$ for a constant $\mathrm{C}$ and every $\mathrm{v} \in \mathrm{H}$. In this case, by Lax-Milgram Lemma, the equation has a unique solution. Our problem is equivalent to find $u$ such that

$$
(\mathrm{Lu}) \mathrm{v}=\mathrm{f}(\mathrm{v}), \forall \mathrm{v} \in \mathrm{H}
$$

Now let $\Psi, \Phi, \Lambda$, and $\Lambda_{\mathrm{i}}$ be as the previous section. Projecting the problem ontoH $H_{i}=\operatorname{span}_{\Lambda_{\mathrm{i}}}$, we can again apply the Lax-Milgram Lemma and conclude that the problem

$$
\left(\mathrm{Lu}_{\mathrm{i}}\right)(\mathrm{v})=\mathrm{f}(\mathrm{v}), \forall \mathrm{v} \in \mathrm{H}_{\mathrm{i}},
$$


has a unique solution. If there exists a constant $M$ such that $\left(\mathrm{S}_{\mathrm{i}}^{\prime}\right)^{-1} \leq \mathrm{M}, \forall \mathrm{i} \in \mathbb{N}$, similar to the previous section we can show that

$$
\mathrm{u}=\sum_{\lambda \in \Lambda}\left\langle\mathrm{f} \mid \psi_{\lambda}\right\rangle\left(\mathrm{S}^{\prime}\right)^{-1} \phi_{\lambda}
$$

and

$$
\mathrm{u}_{\mathrm{i}}=\sum_{\lambda \in \Lambda_{\mathrm{i}}}\left\langle\mathrm{f} \mid \psi_{\lambda}\right\rangle\left(\mathrm{S}_{\mathrm{i}}^{\prime}\right)^{-1} \phi_{\lambda}
$$

The following theorem holds.

Theorem 3.3. Let $\mathrm{L}: \mathrm{H} \rightarrow \mathrm{H}^{*}$ be a bounded, self adjoint and $\mathrm{H}$-elliptic. If there exists a constant M such that $\left(\mathrm{S}_{\mathrm{i}}^{\prime}\right)^{-1} \leq \mathrm{M}, \forall \mathrm{i} \in \mathbb{N}$, then $\mathrm{u}_{\mathrm{i}} \rightarrow \mathrm{u}$ as $\mathrm{i} \rightarrow \infty$ and there exists a constant $\mathrm{c}$ such that

$$
\left\|\mathrm{u}-\mathrm{u}_{\mathrm{i}}\right\|_{\mathrm{H}} \leq \operatorname{cinf}_{\mathrm{v} \in \mathrm{H}_{\mathrm{i}}}\|\mathrm{u}-\mathrm{v}\|_{\mathrm{H}} \text {. }
$$

Proof. Subtracting (3.6) from (3.5) with $v \in \mathrm{H}_{\mathrm{i}}$, we obtain

$$
\mathrm{L}\left(\mathrm{u}-\mathrm{u}_{\mathrm{i}}\right) \mathrm{v}=0, \forall \mathrm{v} \in \mathrm{H}_{\mathrm{i}} \text {. }
$$

By the ellipticity of $\mathrm{L}$,

$$
\mathrm{C}\left\|\mathrm{u}-\mathrm{u}_{\mathrm{i}}\right\|_{\mathrm{H}}^{2} \leq\left(\mathrm{L}\left(\mathrm{u}-\mathrm{u}_{\mathrm{i}}\right)\right)\left(\mathrm{u}-\mathrm{u}_{\mathrm{i}}\right)=\left(\mathrm{L}\left(\mathrm{u}-\mathrm{u}_{\mathrm{i}}\right)\right)(\mathrm{u}-\mathrm{v}) \leq\|\mathrm{L}\|\left\|\mathrm{u}-\mathrm{u}_{\mathrm{i}}\right\|_{\mathrm{H}}\|\mathrm{u}-\mathrm{v}\|_{\mathrm{H}},
$$

Therefore

$$
\mathrm{C}\left\|\mathrm{u}-\mathrm{u}_{\mathrm{i}}\right\|_{\mathrm{H}} \leq\|\mathrm{L}\|\|\mathrm{u}-\mathrm{v}\|_{\mathrm{H}}, \forall \mathrm{v} \in \mathrm{H}_{\mathrm{i}},
$$

that means

$$
\left\|\mathrm{u}-\mathrm{u}_{\mathrm{i}}\right\|_{\mathrm{H}} \leq(\|\mathrm{L}\| / \mathrm{C}) \inf _{\mathrm{v} \in \mathrm{H}_{\mathrm{i}}}\|\mathrm{u}-\mathrm{v}\|_{\mathrm{H}}
$$

as we desired.

We can express the problem (3.6) in the form of a linear system of the finite dimensional space $\mathrm{H}_{\mathrm{i}}$. If we write $u_{i}=\sum_{j=1}^{i} \xi_{j} \phi_{j}$ then (3.6) is equivalent to a linear system

$$
A_{i} \xi=b \text {, }
$$

where $\xi=\left(\xi_{\mathrm{j}}\right) \in \mathbb{R}^{\mathrm{i}}$ is the unknown vector, $A_{\mathrm{i}}=\left(\left(\mathrm{L} \phi_{\mathrm{j}}\right)\left(\phi_{\mathrm{j}}\right)\right)_{\mathrm{i} \times \mathrm{i}}$ is the stiffness matrix and $\mathrm{b}=$ $\left(\mathrm{f} \phi_{\mathrm{j}}\right) \in \mathbb{R}^{\mathrm{i}}$. Since $\mathrm{L}$ is bounded and elliptic then we can define a bounded and elliptic bilinear form $\mathrm{a}: \mathrm{H} \times \mathrm{H} \rightarrow \mathrm{R}$ by $\mathrm{a}(\mathrm{u}, \mathrm{v})=(\mathrm{Lu}) \mathrm{v}$. That is there exist constants $\mathrm{M}$ and $\mathrm{C}$ such that

$$
|\mathrm{a}(\mathrm{u}, \mathrm{v})| \leq \mathrm{M}\|\mathrm{u}\|_{\mathrm{H}}\|\mathrm{v}\|_{\mathrm{H}}, \mathrm{a}(\mathrm{v}, \mathrm{v}) \geq \mathrm{C}\|\mathrm{v}\|_{\mathrm{H}}^{2} .
$$

Now we consider the equivalent problem to find

$$
\mathrm{u} \in \mathrm{H}, \mathrm{a}(\mathrm{u}, \mathrm{v})=\mathrm{f}(\mathrm{v}), \forall \mathrm{v} \in \mathrm{H} .
$$

In order to seeking the approximated solution $u_{i} \in H_{i}$, we project this problem onto $H_{i}$,

$$
\mathrm{u}_{\mathrm{i}} \in \mathrm{H}_{\mathrm{i}}, \mathrm{a}\left(\mathrm{u}_{\mathrm{i}}, \mathrm{v}\right)=\mathrm{f}(\mathrm{v}), \forall \mathrm{v} \in \mathrm{H}_{\mathrm{i}} .
$$

This solution procedure is called the Galerkin method. Since $H_{i} \subset H_{i+1}$ and $\overline{U_{i} \geq 1} \bar{H}_{i}=H$, then there exist a sequence $\left(v_{i}\right)_{i \geq 1}, v_{i} \in H_{i}$, such that $\left\|u-v_{i}\right\|_{H} \rightarrow 0$ as $i \rightarrow \infty$. Applying the previous theorem,

$$
\left\|\mathrm{u}-\mathrm{u}_{\mathrm{i}}\right\|_{\mathrm{H}} \leq \mathrm{c}\left\|\mathrm{u}-\mathrm{v}_{\mathrm{i}}\right\|_{\mathrm{H}} .
$$

Therefore we conclude $\left\|\mathrm{u}-\mathrm{u}_{\mathrm{i}}\right\|_{\mathrm{H}} \rightarrow 0$ as $\mathrm{i} \rightarrow \infty$, that means the Galerkin method converges. 


\section{References}

[1] K.G. Atkinson, Iterative variants of the Nystrom method for the numerical solution ofintegral equations, Numer. Math. 22 (1973) 17-31.

[2] M. Bahmanpour, M. A. Friborzi Araghi, Numerical solution of Fredholmand Volterraintegral equation of the first kind using wavelets bases,J. Math. Computer Sci. 5 (2012) 337-345.

[3] W. Briggs, A Multigrid Tutorial, society for Industrial and Applied Mayhematics, Philadel-

phia, PA, 1987.

[4] P.G. Casazza, The art of frame theory, Taiwaness J. Math. 4 (2000) 129-201.

[5] O.Christensen, An Introduction to Frames and Riesz Bases, Birkhauser, Boston, 2003.

[6] A. Cohen, W. Dahmen, R. DeVore, Adaptive wavelet methods for elliptic operator equations:convergence rates, Math. of comp. 70:233 (2001) 27-75.

[7] A. Cohen, W. Dahmen and R. DeVore, Adaptive wavelets methods II-beyond the elliptic case,Found. of Comp. Math. 2 (2002) 203-245.

[8] S. Dahlek, M. Fornasier and T. Raasch, Adaptive frame methods for elliptic operator equa-tions, Advances in comp. Math. 27 (2007) 27-63.

[9] S. Dahlek, T. Raasch and M. Werner, Adaptive frame methods for elliptic operator equations:the steepest descent approach, IMA J. Numer. Anal. 27 (2007) 717-740.

[10] M. M. Shamaooshaky, P. Asghari, H. Adibi, The numerical solution of non linier Fredholm-Hammerstein integral equation of the second kind utilizing Chebyshev wavelets, J. Math. Computer Sci.10 (2014) 235-246.

[11] R. Stevenson, Adaptive solution of operator equations using wavelet frames, SIAM J. Numer.Anal. 41 (2003) 10741100 . 